\title{
The two faces of user involvement: Everyday life and local context
}

- an ethnographic field study of user involvement in development of an educational programme for people with rheumatoid arthritis

Tine Mechlenborg Kristiansen, Rasmus Antoft, Jette Primdahl \& Kim Hørslev Petersen

Faggruppen for Epidemiologi og Folkesundhedsvidenskab, AAU

Department of Sociology and Social Work, AAU

Kong Chr. X's Gigthospital

tmk@hst.aau.dk,ras@socsci.aau.dk,jprimdahl@gigtforeningen.dk,

khorslevpetersen@gigtforeningen.dk

Kristiansen, T.M., Antoft, R., Primdahl, J. \& Petersen, K.H. (2015). The two Faces of User Involvement: Everyday Life and Local Context, Tidsskrift for Forskning $i$ Sygdom og Samfund, nr. 22, 19-44

In most developed countries, healthcare systems are increasingly faced with political demands to involve users in the planning and development of their services. This article reports findings from an ethnographic fieldwork that investigated an inter-organizational project involving user representation. The project was set up to develop an educational programme for people with rheumatoid arthritis (RA). By investigating user representatives' experiences, our aim was to bring to light more general determinants and conditions of user involvement in health services. Drawing on an analytical framework within everyday life sociology, the analysis explored the dual concept of "conditions and conditionality", 
metaphorically described in this article as "the two faces of user involvement". From one perspective, everyday life experiences - living with $R A$, encounters with the health system and professional identities and work life - conditioned user representatives' participation in the project. From another perspective, the local institutional context and interactions within the project framework conditioned the way in which users are involved. The ways in which these conditions changed over time are described, in relation to the specific spatial, temporal and social developments in both the everyday lives of the user representatives and in the local project.

\section{Background}

In the majority of economically developed countries, governments across the political spectrum have a stated aim to increase the involvement of service users in the management and provision of health services (Martin \& Finn 2011; Reddel \& Woolcock 2004). A variety of reasons have been suggested for this growing interest in user involvement, including the need for greater direct public accountability (Martin 2008a), the argument that user involvement might reduce the "democratic deficit" between electoral processes and the implementation of policies by state administrators (ibid.), the assumption that user involvement could improve the quality of services (Coulter \& Ellins 2006; Crawford et al. 2002; Fudge 2006; Freil \& Lehmann Knudsen 2009; Tempfer \& Nowak 2011), and the argument that user involvement is a sound democratic principle and a response to the emergence of a more demanding citizenship (Martin 2008a).

This growing interest is mirrored in user involvement literature; a growing number of qualitative studies discuss a range of experiences and perspectives of user involvement (Barnes, Newman, Knops \& Sullivan 2003; Contandriopoulos 2004; Fudge 2006; Wolfe \& McKevitt 2008; Hodge 2005; Martin 2008a; Martin 2008b; Martin \& Finn 2011; Crawford et al. 2002; Willis et al. 2011).

A dominant approach in user involvement literature involves studies that take a structural perspective on power. A number of studies describe how user involvement is a strategy used by political, administrative and clinical systems to control the processes of user involvement, using users to legitimize decisions rather than practicing user involvement (Constandriopoulos 2004; Hodge 2005; Martin $2008 b$ ). In contrast a few other studies that take a micro-level approach explore the personal gains and costs of participating in the development and planning of health services (Fudge, Wolfe \& McKevitt 2008; Fox 2011). Barnes et al. highlight the 
importance of examining the micro-politics of interactions in their specific forms. They point to the great significance of contextual determinants in the negotiation of legitimacy and state that further research is needed to identify the specific factors activated in, and through, processes of user involvement that influence such negotiations (Barnes, Newman, Knops \& Sullivan 2003).

This article attempts to contribute to this micro-sociological tradition of examining interactions in their local contexts; however, it at the same time also includes the context of user representatives' everyday lives, in order to develop a broader picture of the dual concept of the conditions and conditionality of user involvement (Bech-Jørgensen 1994).

The fieldwork investigated an inter-organizational project that involved user representatives, which was set up to develop a new educational programme for people with rheumatoid arthritis (RA). Because the involvement of users was stated as an overall aim, the project was considered to represent an appropriate general case of user involvement.

The overall research question was: how did user representatives experience user involvement? The purpose of the analysis was to reveal more general determinants and conditions of user involvement in health services by investigating user representatives' experiences. For the purpose of analytical clarity, we adhere to Kleinman's classical distinction between taking an analytical perspective towards the phenomenological experiences and sensations of people living with chronic illness (the illness perspective), and the health professional practice of diagnosis and categorization (the disease perspective). The analytical focus of our study is based on the former perspective (Kleinman 1988). We recognize, however, that in the everyday practices of both lay people and health professionals, the two perspectives might be interwoven (Bury 1982; Gannik 2005). For example, in engaging with bio-medically oriented health professionals, lay people with chronic illnesses might partially integrate a medical disease perspective in their experience and understanding of their own illness. Similarly, health professionals might be influenced in their daily practice by both their own everyday life experiences related to health and illness and those of their patients.

Drawing on an analytical framework within the sociology of everyday life, developed by the Danish sociologist Birte Bech-Jørgensen (Bech-Jørgensen 1994), the two faces of user involvement are explored in the analysis: Firstly, how everyday life experiences condition user representatives' participation in the project and, secondly, how the local context and interactions within the project framework condition the way in which users are involved. Furthermore, the ways in which 
these conditions are reshaped and changed over time are described, depending on the specific spatial, temporal and social developments in both the everyday lives of the user representatives and in the local project.

\section{Method}

\section{Empirical Field and Participants}

This study explored an inter-organizational project that developed a new educational programme (hereafter: programme) for people with RA over a period of 14 months. The project was conducted collaboratively between rheumatic departments at two hospitals and two local community healthcare centres in Denmark ${ }^{1}$. User involvement was stated as a central aim and users were involved in order to develop a more patient-centred and tailored programme.

The project was divided into three phases: an initial phase for the development of ideas, a second phase to design the programme and a final phase to define the health educational basis and prepare the detailed delivery of the programme. The project was conducted on different structural levels; for example, a joint project group was set up to collaborate with separate, inter-organizational groups in each of the cities where the programme was delivered. The joint project meetings alternated between working together in plenary sessions and in break-out groups.

The steering group was made up of a management representative from each of the four organizations participating in the project, two user representatives, who represented patients with RA at the two participating hospitals, a project manager and a project coordinator, who had overall responsibility for the project. The project coordinator was employed exclusively to facilitate the development of the programme and was externally recruited.

The development of the programme took place in an inter-disciplinary and inter-organizational project group that consisted of 15 health professionals from the four participating organizations, apart from one who was recruited externally, and five user representatives who were outpatients at the two participating hospitals.

The members of the project group working at the hospitals comprised two rheumatologists, two nurses, two physiotherapists, an occupational therapist and a social worker. From the local community healthcare centres, two nurses, two 
occupational therapists, a midwife, who was also a local coordinator of patient education programmes at the community level and a dietician participated. A psychologist was externally recruited.

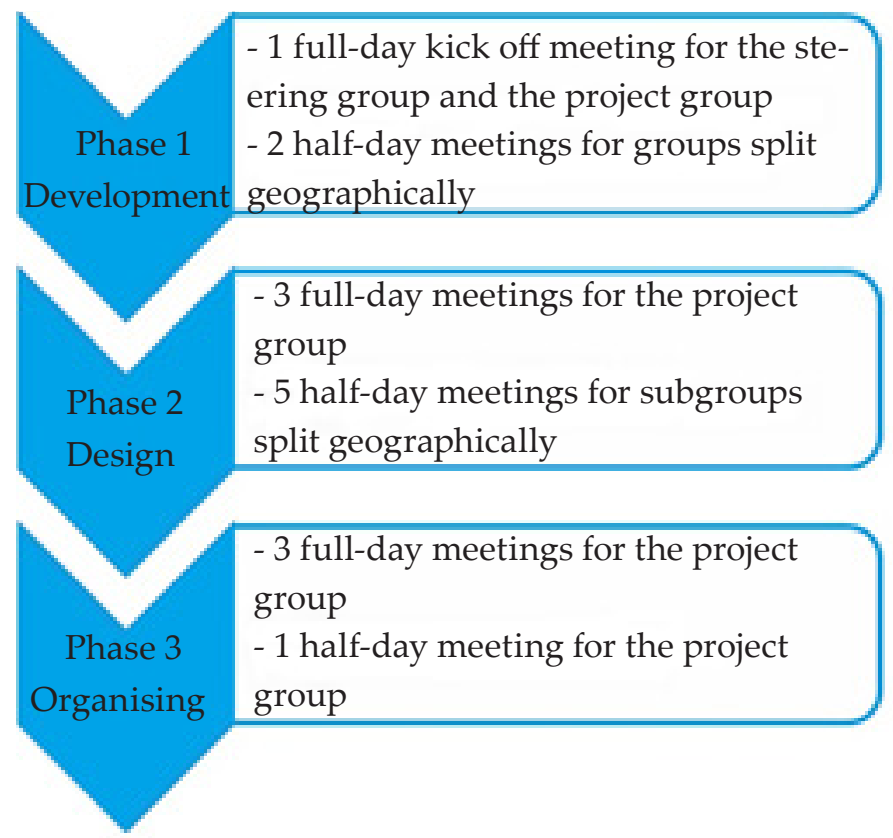

Figure I: Outline of project meeting structure

The user representatives were invited from a previous focus group study on everyday life and RA whose aim had been to explore how RA affected everyday life and to draw some general implications related to patient education (Kristiansen, Primdahl, Antoft \& Hørslev-Petersen 2012). The participants in these previous focus group interviews were recruited from the same hospitals involved in the inter-organizational project and were selected from patients' medical records by clinical staff according to purposeful sampling criteria, with the aim to span the greatest possible variation in age, educational status, gender, and disease duration. A total of 32 people with RA had participated in the focus group interviews and they were all invited to participate in the project. The only formal requirement was a willingness to contribute with personal experiences and wishes concerning patient education. In the end, five people volunteered to take part in the project and were involved. Three of the user representatives were women and two were men. The age range was 33 to 67 and the time since diagnosis ranged from 3 to 27 years. One had a clerical background, two had a vocational background and 
two had a teaching background. Two had retired early due to RA $^{2}$ and the other three all had subsidized jobs ${ }^{3}$.

\section{Research ethics}

The Regional Research Ethics Committee of Southern Denmark was informed about the study but considered that an approval was unnecessary, as it was not a part of a biomedical study. The study was reported to the Danish Data Protection Agency and approved on 26th October 2010. The project group was informed, orally and in writing, about the aim of the study. As key informants, the user representatives were given further written and oral information about the study and gave their informed consent. The names of all participants have been anonymized. However, the participants might be recognizable to each other, to other health professionals in the respective hospitals and to families and friends. Although all informants gave their consent to participate in the study, the fieldworker soon realized that the notion of informed consent is ambiguous. Situations arose during fieldwork that raised ethical questions concerning her role. Gradually, she came to be regarded by the informants as a "confidant" stranger who they could trust. Some informants told her about aspects of their lives that involved their intimate relations, which she regarded as very private. In one case, she chose not to include field notes in the data, and in other cases she decided not to use certain elements in the presentation of the findings, although they were included in the analysis. The decisions were based on "ethical situationism", whereby one carefully weighs the prospects and consequences for particular research strategies in particular situations (Hammersley and Atkinson 2007; Hastrup 2009; Hviid Jacobsen and Kristiansen 2006).

\section{Conducting fieldwork}

The study took the form of an ethnographic fieldwork (Hammersley \& Atkinson 2007; Wadel 1991) and was carried out by the first author. The fieldwork focused on the work of the project group, as it was this group that had the mandate to develop the programme.

The data sources are described in detail in the figure below. 


\begin{tabular}{|l|l|}
\hline Field notes & $\begin{array}{l}\text { - Field notes from eight plenary meetings } \\
\text { and seven geographically split meetings } \\
\text { - Reflexive diary }\end{array}$ \\
\hline $\begin{array}{l}\text { Interviews and con- } \\
\text { versations with user } \\
\text { representatives }\end{array}$ & - Five interviews before participating in the \\
project & -23 telephone interviews during the process \\
& - Email correspondance \\
& - Five interviews after the development of \\
& the educational programme \\
\hline Background information & Letter to the user representatives from the \\
from the project & project manager \\
& Emails from the project coordinator to the \\
& project group \\
& Materials produced in and for meetings \\
\hline
\end{tabular}

Figure II Data sources

The primary data sources were participant observation and individual interviews, supplemented by background information related to the project.

The participant observation focused on the interactions between the members of the project group. Attention was paid to how both the formal structures of the meetings and informal processes affected the ways in which user representatives' knowledge of everyday life and their experiences of a lived life with RA contributed to the project.

The field notes from the participant observation were descriptive. In addition, a reflexive diary was written by the first author during the fieldwork. It contained self-evaluations of the role of the fieldworker and theoretical and analytical ideas (Emerson, Fretz \& Shaw 1995). This generated new questions, which were asked and examined as part of the subsequent interviews and as part of more informal conversations at the project meetings.

The ethnographic interviews focused on the users' experiences of participating in the project and on their reflections about their own everyday life with RA. The initial and final interviews took place in the users' homes, and all interviews were recorded and transcribed verbatim. The interviews took between 1.5 and 2 hours and were semi-structured. For practical reasons, the interviews conducted during the process were conducted as telephone interviews. The aim was to gain a detailed description of the individual user representative's experiences of participating in the meetings. Detailed notes were taken immediately after the interviews. 


\section{Analytical framework and concepts}

The overall analytical framework of the analysis is adapted from a social phenomenological perspective of everyday life sociology. It is inspired, in particular, by the Danish sociologist Birte Bech-Jørgensen and her analysis of the triadic relationship between everyday life as it is lived, the conditions of everyday life and the way in which individuals handle these conditions (Bech-Jørgensen 1994). She differentiates between activities on three structural levels: the unnoticed activities of everyday life, symbolic meaning universes and societally constructed institutions. The individual is faced with different conditions on each of the three structural levels. These conditions are structured across time, space and social relations and are continuously shaped and reshaped through the activities in everyday life (Bech-Jørgensen 1994; Bech-Jørgensen 2002).

As the aim of our analysis was to reveal more general determinants and conditions of user involvement in health services by way of an exploration of how the user representatives experienced user involvement, it seemed relevant to adopt this general framework. To this end, an analysis was conducted of the two faces of user involvement: in relation to both the everyday lives of the user representatives and the local institutional conditions in the project.

In the following section, we introduce the analytical concepts used in the analysis of the two faces of user involvement.

\section{The conditions of everyday life}

In the first part of the analysis, we focused on how experiences and knowledge from everyday life shaped the way in which the individual users took part in the project. We adhere to Bech-Jørgensen's definition of everyday life: "Life as it is lived, maintained, renewed and recreated everyday..." (ibid.). According to BechJørgensen, while it is not possible to define everyday life sociologically, it is possible analytically to describe and analyze the conditions of everyday life and the way in which individuals handle these conditions. This is what we aimed to do. During the fieldwork and, in particular, during the ongoing interviews with user representatives, the fieldworker focused on exploring their everyday lives in order to grasp how their lives related to their involvement in the development of patient education. It was soon clear that the everyday lives of the users conditioned in certain ways how they could participate. Conversely, participation in the project 
also had an impact on their everyday lives. However, this latter perspective has not been the focus of this paper.

\section{Institutional and interactional conditions}

In the second part of the analysis, we focused on how the local institutional context influenced the involvement of the users, partly through an analysis of the negotiation of roles and knowledge and partly through an analysis of social and symbolic integration.

The role concept is adapted from Berger and Luckmann's analysis of the social construction of knowledge (Berger \& Luckmann 1966). According to Berger and Luckmann, roles arise out of the division of labour in society and the concomitant social distribution of specialized knowledge and, as such, roles are closely associated with functions in society. As part of the secondary socialization process, the individual internalizes his/her roles and they become part of a general identity that is never fully developed. Each role inhibits a common stock of knowledge (ibid. ${ }^{4}$ ) and certain standards of role performance, accessible to those who are potential performers of the role. This means that, from the perspective of the role "owner", each role carries with it a social appendage of knowledge. Within a society, some roles are more important than others, as they might symbolize important functions in society (ibid.). We have used Berger and Luckmann's role concept to demonstrate how the different roles and the initial "hierarchy of knowledge" are negotiated and changed over time.

The social integration within the project was analyzed with reference to the spatial, temporal and social development of the relations in the project group (Bech-Jørgensen 2002; Jenkins 2008). The creation of a more symbolic integration, i.e. the generation of a sense of shared belonging and a strong commitment to the project, was also analysed, both with reference to the integration within the project group and between the user representatives (ibid.).

\section{Data analysis}

The first author performed the analysis, which was carried out by coding and interpreting the data. The intention was that the interpretations would be as close as possible to the users' own interpretations of their involvement, through second 
order interpretation (Schutz 2005). The results were continuously discussed with co-authors.

Each data source was read several times. NVivo version 9 software was used to facilitate systematic structuring of the data and analytical memos inspired the analyses and aided reflection on the researchers' role during the entire analysis process. The analysis was conducted as a qualitative content analysis (Coffey \& Atkinson 1996). Firstly, an open coding was carried out inductively; all data were coded. Secondly, inspired by Bech-Jørgensen's analytical framework, the analytical idea of "the two faces of user involvement" was developed, and was used as the "sorting principle" for the categorization and conceptualization of the coded data. Data were grouped into two overall categories. One category included data that gave information about the internal conditions related to the user representatives' everyday life experiences. The second category included data about the institutional and local project-related conditions of user involvement (Bech-Jørgensen 1994, Bech-Jørgensen 2002). Within this general framework, subcategories were developed to describe the different factors that contributed to the conditioning of user involvement. These categories were linked to analytical concepts derived from everyday life sociology (Bech-Jørgensen 1994; Bech-Jørgensen 2002; Berger and Luckmann 1966) in order to strengthen the analytical generalizability (Atkinson 1995; Coffey \& Atkinson 1996). Finally, the results were compared with the initial, open coding to check that none of the empirical findings had been overlooked.

\section{Results}

The underlying conditions of everyday life and how they affected the way in which user representatives experienced participation are described below, together with conditions relating to the local institutional context and how they affected the way user involvement was practised.

\section{Everyday Life Experiences}

Experiences and knowledge from their own everyday lives shaped the user representatives' expectations of the project and influenced how they took part. We analyze below the three significant areas of everyday life that affected participation: 
illness experiences from living with RA, experiences from encounters with the health system and health professionals, and work experiences.

\section{Illness experiences from living with RA}

The users considered their actual disease activity to be an important factor, in that it either facilitated or limited their scope of participation.

Martin and Peter, in particular, experienced significant fluctuations in their disease activity during the project. Of all the informants, Martin was the one most affected by RA, with severe physical impairments and visible deformities of the joints. During the second phase of the project, his condition worsened because of complications related to his RA. He had to leave the project due to hospitalization and, in the end, he permanently withdrew from the project. During the final interview, after he had withdrawn, Martin described how he had experienced the withdrawal:

Martin: I really felt, whenever I couldn't make the meeting, I felt I missed so much.

Interviewer: Do you think it has affected the whole process for you, somehow?

Martin: Yes. I think so. It went all wrong near the end, when I couldn't join in at all. I wasn't off the rails as such, but I was, my physical and psychological situation forced me to realize that I couldn't. I had to give up and drop out. Oh it was really hard, I must say.

Interviewer: You say it was really hard. Would you tell me a little more about it?

Martin: Yes. I mean, it's the first time in my life where I had to give up on something and realize that I couldn't complete it.

Later in the interview, Martin talked about how he felt confident that the other user representatives would be able to represent the "patient group" and that this confidence made it easier for him to opt out.

Interviewer: Ok, does that mean that it was also a relief for you to opt out?

Martin: Yes, actually, yes. Yes. I think I felt better when I had told them that I had to opt out. It sort of relieved me from this burden I felt on my shoulders. 
(Interview Martin, January 2012)

The other users also confirmed that illness activity and severity conditioned how they could participate and the female informants said that they regarded the stability of their RA as a precondition for their active participation in the project.

Another aspect of the illness experience was how the users had come to terms with RA. Inge, Anne and Tina regarded it as a precondition for participation that they had come to terms with RA as part of their lives and identities. All three women considered that it was only possible for them to contribute to the project because they had gone through their own personal processes of accepting the illness as a new and permanent aspect of life. Reflecting on a time when they had been frustrated about the lack of effective medical treatment and the social and psychological consequences of RA, they could not imagine how they would have been able to contribute or help others, at a time when they felt so affected themselves. Anne and Inge regarded the years of living with RA and the many experiences gained as qualifications: experiences of a wide range of treatment strategies and pharmacological treatments and of handling the social consequences of RA and psychological reactions to living with the illness. They considered that these experiences qualified them to help health professionals understand better the experience of living with RA and to get a more complete picture of the illness.

Anne states:

"You have to know yourself, have many years of experience and to have gone through the whole process."

(Interview Anne, November 2010)

\section{Experiences of Engaging with the Health System and Health Professionals}

The user representatives gained a range of experiences from their contact with, and engagement in, the health system. These experiences had an impact on their motivation to get involved, on the stock of illness-related knowledge that they brought with them and their expectations of their own role as "patient representatives". 
The experiences from engaging with the health system and health professionals differed significantly among the user representatives. Some had positive experiences that they wanted to pass on to others, while others had negative experiences which they did not want others to experience. Both Anne and Peter related how they had experienced a narrow, disease-oriented focus related to the treatment of RA and a lack of empathy from the health professionals, especially the rheumatologists. The example below is from the first telephone interview with Peter:

Peter says that he has had very bad experiences with the rheumatologists. The treatment has been ok, but they don't have any human interaction qualifications. Peter tells about a consultation, where his rheumatologist came running down the corridor in a hurry and said to him: "I'm late, I only have a few minutes for you". Peter says that: "it takes the wind right out of your sails, and you get the feeling that you are only causing trouble" ... Peter continues: "this is exactly the experience I've had, being treated as 'a rheumatoid arthritis' and not as a human being with RA".

Later in the interview, he states that this has been a motivating factor in his decision to get involved.

Peter says that's why he did not have any doubt about joining the project heart and soul. He wants to equip other patients to engage with the health systems.

(Descriptive notes, telephone interview Peter, January 2011)

The encounters with the health system also provided user representatives with a certain stock of knowledge about the treatment of RA and how to handle symptoms in everyday life. They also developed a "disease-specific" vocabulary that allowed them to understand and join the interdisciplinary discussions at project meetings.

Inge and Tina both had previous experience of patient education in terms of interdisciplinary information and treatment during hospitalization. They both regarded the knowledge and information gained during hospitalization and patient education as preconditions for their participation in the project. During the final interview, Tina reflected on the significance of this earlier patient education:

Tina: Well, I don't think that I would have been able to take part in the project in the same way if it hadn't been for the course in understanding your illness, because 
you know, I had already heard of many of the topics discussed at the project meetings.

(Interview Tina, January 2012)

However, not all user representatives felt that they had received sufficient treatment and information. During a session where they worked alone as a group, they talked about the treatment and information that they had received at their respective hospitals, and Anne exclaimed:

"Oh, you got it all. It seems easier if you come from your hospital." (Anne talks very loudly now and seems frustrated.)

(Field notes, November 2011)

Finally, the encounters with the health system shaped the role expectations of the user representatives. In the invitation letter from the project manager, they were invited to join the project as "patient representatives, representing their own experiences and wishes concerning patient education". Although the five user representatives did not have exactly the same role expectations, and they could change over time, at the beginning they all associated the role of a "patient representative" with a consultative role of patients with a right to be heard and listened to, but without the power to make decisions. Anne expressed her expectations like this:

Anne: I am used to working in an interdisciplinary way, and I know that the language used will be technical and professional, a language that I might not know very well. But yes, of course, it requires a bit of effort when you have to work together. You also have to speak in a way that everybody will understand somehow, and you should ask, "What do you mean, when you say that?" I think, well maybe I should be a bit humble, because we are only there as patients. Of course, we have experiences that they can use, but we are not there as if we have got the idea, we have just been asked whether we want to participate, and I think that's fantastic, that we are allowed to.

(Interview Anne, November 2010)

They all expressed gratitude towards the project management and felt honoured to participate. 


\section{Experiences from work life}

Since the project meetings were held during normal working hours, user representatives who were still employed had to take time off to be able to join the meetings. It was agreed that their employers would be financially reimbursed for time lost. None of the user representatives worked full-time. They all agreed that participating in the project would be incompatible with full-time work because they would not have sufficient energy to take part. During the first interview, Tina related:

"I have more energy now because I'm on maternity leave ... actually, I can't imagine working full-time at all. If I did, eh, I really think that my family would fall apart."

(Interview Tina, November 2010).

Anne and Peter had a teaching background and both felt that their professional experience provided a special precondition for participation in the project. At the same time, they considered that the project offered new opportunities to develop themselves personally and professionally.

Peter had experienced a gap in his life after the RA put a stop to his professional career. For him, the project represented a chance to recreate meaning in his life by making use of both his personal experiences of living with RA and his professional background. RA suddenly became a qualification that could be drawn upon in a positive and meaningful context. In a telephone interview during the final phase of the project, when the health pedagogical foundation of the programme was being defined, Peter reflected on the following:

I say to Peter that I have thought about how, as a teacher, he experiences his contribution to the project, both in terms of his professional knowledge and his experience of living with RA. I ask Peter how he uses these two separate aspects of knowledge, for example during group discussions last Tuesday, where a pedagogical topic was under discussion. Peter says that he actually hasn't thought about it, that he supposes that he participates as "me" and that he thinks that he uses his professional knowledge as a supplement to his experiences with RA. He says "now that I can use the RA, it's become a qualification, it's quite a funny thing".

(Descriptive notes, telephone interview Peter, October 2011) 


\section{Conditions related to the local context of the project}

Besides the conditions related to the everyday lives of the user representatives, the local institutional context of the project also represented a set of conditions that affected how the users were involved. These conditions were analyzed from a process perspective, focusing on changes over time.

Breaking down the traditional hierarchy of knowledge - the role of the project coordinator

The meetings in the project group were all held externally to the four organizations taking part in the project, so that no-one was on their home ground. Through active management of the meetings, the project coordinator made sure that everyone had the opportunity to contribute with their own experiences and wishes. In the discussions, the project coordinator actively integrated the stories and metaphors that the user representatives had related on previous occasions. The meetings in the two geographically split subgroups had a clear structure, involving a dialogue where everyone took turns, and where all group members were asked to reflect on "thoughts since the last meeting" and to comment on drafts written by the project coordinator (field notes). The project group was also encouraged to give written comments to the drafts of the programme. Of the user representatives, only Anne wrote comments and formulated her own ideas and proposals. Anne explained it like this:

"When I am encouraged to contribute my ideas, then I think very specifically ... I

might be a little off the mark, seeing it from my perspective as a teacher."

(Interview Anne, January 2012)

The other user representatives explained why they did not contribute in the same way: it was either because they agreed with the drafts or because they did not have the physical and mental energy to do so.

From the very beginning of the process, the project management had a particular focus on the development of a health pedagogical basis for the programme. This emphasis on pedagogical knowledge was mirrored by a differentiation in the way the individual user representatives were involved in practice. From the be- 
ginning of the process, the project coordinator addressed Anne and Peter as "the teachers" and referred to their pedagogical experiences in her own presentations. In the final phase of the project, the differentiation increased, as Anne and Peter were directly consulted by the project coordinator. They were asked for ideas to help come up with the best health pedagogical model to describe the content, the goals and the evaluation of the programme. In one project group meeting, Anne's and Peter's special role was described by the project coordinator when she addressed them as her "pedagogical consultants" (Field note, October 2011).

\section{Interactions and negotiations regarding different roles and forms of knowledge}

All the user representatives felt they were warmly welcomed to the project at the first meetings in both the whole project group and the two geographically split subgroups. They described the health professionals as listening, accommodating and genuinely interested in their personal experiences.

After these first meetings, the users reflected on the ways in which they were involved and interacted with the health professionals. In the project group and in the two geographically split subgroups, they all felt that they were involved on an equal footing with the professionals, because the project coordinator ensured that all group members were heard. In contrast, they experienced the inter-organizational and inter-disciplinary group sessions in the second phase of the project as discussions between different organizational and professional interests, and as negotiations about which roles should be developed in the programme and who should adopt them.

Anne and Martin both felt that, although the health professionals listened to them, their experiences were not valued to the same extent as the health professionals' knowledge. Anne had expected that it would be easy for her to collaborate with the health professionals, as she was used to interdisciplinary collaboration in her own work. Martin had expected an equal collaboration based on his experiences from earlier hospitalizations. Tina's and Inge's expectations of involvement were met, as they had expected to be heard as patients with their own experiences and wishes, without having a significant influence on specific decisions.

Inge reflected on a group session where she experienced a situation that seemed to be a dispute about words and where the language the professionals used made 
her feel unable to contribute to the group discussions. She said that, for Peter, it was quite different because "he is both a professional and a patient" (field note, May 2010). Peter himself confirmed Inge's interpretation of his role. He defined himself both as a professional contributing with professional, pedagogical and consultant skills and as a patient with personal experiences. He did not distinguish between those skills and roles, but instead integrated the skills and roles in the "daily" work of the project.

In the final phase of the project, the structure of the new programme was agreed upon, future functions were defined and new relations and role definitions were negotiated between the project coordinator, the health professionals and the user representatives. It was decided that the user representatives be assigned a mentoring function and, together with the two local coordinators, they would be the only ones to participate in the whole educational programme. The final programme consisted of five thematic meetings, each involving both structured teaching led by health professionals and more unstructured dialogue and exchange of experiences facilitated by the mentors.

At this point in the process, everyday life experiences had become considered as expert knowledge that was fundamental to the development of a core aspect of the programme. The user representatives felt that their everyday life experiences were given more weight due to their formal role as mentors. In particular, it was the user representatives with a professional educational background who engaged in the negotiations with more self-confidence. This self-confidence was expressed by Anne in the final interview:

Anne: In this last phase, we have been working a lot in our own group, so we haven't come across this: "No, that's not possible", because we are just sitting in our own group and we get done, what we want to get done.

Interviewer: Oh, I see, has it given you more freedom?

Anne: Yes, indeed, it has. Because now we have this freedom within this framework, right. Now the roles have been defined, and we know, oh, this is our responsibility and only this.

(Interview Anne, January 2012) 


\title{
Social integration
}

The local project ran for about 14 months. The extended period of time and the many meetings facilitated the development of social relations across disciplines, organizations and individuals with different backgrounds. The programme meetings included several breaks, allowing time for informal interaction.

The user representatives reflected on and appreciated this gradual social integration, because it meant that it felt more safe and comfortable to participate. The interview extract below describes Tina's reflections during the final interview, when asked how it has been for her to be involved in the project:

\begin{abstract}
"Well, I think the initial uncertainty has gone. I was a little sceptical in the beginning, even though I had volunteered. I remember the first meeting, it was really just a bunch of strangers, all of them (laughs). Now, it has changed; we know each other now, more or less, although some new people have attended. It sort of feels, yes, I think it feels really, really nice. It hasn't been as difficult as I thought it would be ... I mean working together with patients and health professionals. I was slightly concerned about it in the beginning, but it hasn't and it has become easier over time."
\end{abstract}

(Interview Tina, January 2012)

\section{Symbolic integration in the project group and among the user representatives}

Besides facilitating an informal social integration across disciplines, organizations and individuals, the project coordinator seemed to make a conscious effort to create a more symbolic integration, by making use of common symbolic manifestations, with the aim of "generating a sense of shared belonging, through a mask of similarity" (Jenkins 2008). At the end of the second phase, everybody was asked to bring in an object that symbolized their wishes for the programme. The completion of the programme was celebrated by drinking a glass of champagne together. Both events had a ceremonial character.

These attempts at symbolic integration appeared to bear fruit. During the final phase of the process, in particular, the four remaining user representatives identified with the common goals and the common task of the group and developed a strong commitment to the project. During the sessions and interviews they started to refer to the project group as "we", as opposed to "they", which referred 
to the people with RA to whom the programme would be offered. This development seemed to be closely associated to their new functional role as mentors in the programme. In the final interview, Peter stated:

"I'm the ongoing person in the programme, I have committed myself to guide these people through the programme. In fact, I have a very strong commitment to this programme."

(Interview Peter, January 2012)

The user representatives had identified with each other from the beginning of the project. After attending the first project meeting, they all talked about how nice it was to meet others with RA and described how they immediately experienced a mutual understanding based on their common social stock of knowledge (Berger and Luckmann 1966) from shared illness experiences.

Over the following six months, they met at meetings in the project group and in the two geographical groups, but they were not all in the same groups during the group sessions. Peter, Martin and Tina related that they missed talking to the others with RA and Martin said that he had avoided contacting the other users, being conscious of "the rules of the game in the project, with no time to sit and have private conversations ..." (Descriptive notes, telephone interview, June 2011). At the same time, he would have liked the opportunity to socialize more informally with the other user representatives.

In the final phase of the project, the user representatives had formally taken on the role of mentors in the programme and were working together during group sessions. The group sessions were used both to informally share illness experiences and to work on defining their role in the programme in more detail. The group sessions almost always started with informal chatting about illness experiences, for example their experiences of managing symptoms, handling the reactions of others, and experiences of medical treatment and of engaging with the health professionals. The shared space that this created allowed them to reflect on existential matters and provided a locus for the exchange of practical experiences and mutual advice.

For Peter, it was the first time he had met other people with RA, and he enjoyed this confidential space where he could both listen to the experiences of the others and talk about things that he did not talk about with his family. Inge also reflected on this difference in her experiences of living with RA: 
Inge says that she thinks she has contributed more actively to this group, compared to the rest of the process. She says that other users who had not lived with RA for as long as she had needed her experiences and her support during the project period and that it had been nice to be able to help them ... Later, she says that she thinks that she has come to terms with RA and has accepted it as a part of her life. She describes it as "swallowing an elephant".

(Field notes, May 2011)

Besides sharing experiences, the user representatives also became colleagues during the final phase of the project and had a shared task. From the beginning, the group defined a particular division of labour, where Anne and Peter would act as meeting facilitators. Anne's and Peter's professional backgrounds made it obvious both to themselves and the others that they would take on this role. Inge and Tina articulated their recognition of this allocation of roles. In a group session, Inge said: "You are used to writing ..." and Tina commented, "Yes, I think you are very competent ..." (Field notes, October 2011).

\section{Discussion}

Drawing on a social phenomenological perspective and a framework developed within the sociology of everyday life, our analysis of the two faces of user involvement put a dual focus on the conditions of user involvement in healthcare: the everyday life conditions of the individual user representatives and the conditions at the meso-structural level of the local project. Our analysis has demonstrated how these conditions are shaped and reshaped, through a complex interplay between users' everyday lives and the activities and role negotiations within the project.

Our field study demonstrates that there are factors - other than those that traditionally focus on social characteristics - related to the everyday lives of the user representatives that influence their participation (Church et al. 2002; Martin 2008a; Nettleton \& Burrows 2003b; Ziebland 2004). In particular, current disease activity and the severity of symptoms can either facilitate or restrict the possibility of active participation. Willis et al. have also pointed to the severity of the disease to explain the challenges faced by user representatives in maintaining engagement in research over a prolonged period (Willis et al. 2011). Their findings parallel the experiences of one of the user representatives in our study, who finally decided 
to withdraw from the project due to the increased severity of his condition. This might raise the question of unequal conditions of participation.

Referring to Berger and Luckmann's concept of role (Berger \& Luckmann 1966), this field study shows how, over time, symbolic negotiations changed the role of the users and how this role change was facilitated through the proactive work of the project coordinator in breaking down the traditional hierarchy of knowledge forms and integrating the users' everyday life experiences.

Parallel to the recognition of everyday life knowledge, or perhaps even as a precondition of this recognition, it is also shown that, in ascribing a functional and more professional role as mentors, the representation of users became legitimized. This process of role change goes hand in hand with an increased social and symbolic integration (Bech-Jørgensen 2002; Bech-Jørgensen 2004; Jenkins 2008). From the perspective of the user representatives, this transformed the project group into a cohesive group with a common task and a shared identity. The members of the group became team workers in the programme, and at the same time the mentors developed an even stronger common identity.

The issue of professionalization might raise the question of representativeness, a topic that is widely discussed in user-involvement literature (Contandriopoulos 2004; Martin 2008a; Martin 2008b). Acknowledging the proactive role of the project coordinator, it is important to point out that the conditions of involvement were not the same for all the user representatives. Their different work backgrounds and educational status proved to be important factors, leading to both a differentiation in the way they were involved and the way they finally defined their own role.

In this way, our study concurs with other studies that also demonstrate how experiential knowledge is reinforced by certain social characteristics, such as being mobilized, middle-class and having reflexive and communicative skills (Church et al. 2002; Martin 2008a; Nettleton \& Burrows 2003; Ziebland 2004) .

The question of whether or not the commonality of the illness experience is enough to nullify the effect of the potential gap between those "represented" and those who are not remains controversial. The five people with RA represented in this case study had different social characteristics, but they felt a strong and increasing identification with each other and mutual understanding due to their common condition and brought up many similar experiences of living with RA. Their everyday life experiences constituted a common social stock of knowledge (Berger and Luckmann 1966), upon which they could draw. 
One of the limitations of our study is that we explored only one case of user involvement and in relation only to one chronic illness - rheumatoid arthritis. Furthermore, it addressed only the perspective of the user representatives, and not the health professionals' perspective. By drawing on an analytical framework and central concepts from the sociology of everyday life in the conceptualization of the empirical findings, the aim was to strengthen the analytical generalisability of the study (Atkinson 1995; Coffey \& Atkinson 1996). The study design, involving repeated interviews with user representatives, reinforced the findings from participant observation, because the fieldworker was able to question her own observations, assumptions and preconceptions over time. Furthermore, the interviews provided new insights, as the reflections about everyday life with RA and the way it affected participation in the project were facilitated during the relationship developed between the fieldworker and the user representatives in the repeated interviews (Aggergaard Larsen 2010; Bech-Jørgensen 2002).

\section{Conclusion and future perspectives}

Our aim was to reveal some more general determinants and conditions of user involvement in health services by exploring the user perspective. In an analysis of the two faces of user involvement, we documented, firstly, how everyday life experiences conditioned user representatives' participation in the project and, secondly, how the local context and interactions within the project framework affected the way in which users were involved.

As opposed to a power perspective, the filter of everyday life sociology enables us to recognize the agency of users and the potential for developing complementarities between different forms of knowledge, viewing users and health professionals as co-producers, while at the same time focusing on the negotiation of knowledge and expertise over time.

\section{Acknowledgements}

We would like to thank all the people in the project group for tolerating the curious fieldworker at all the meetings (TMK). A special thanks to the user represen- 
tatives for all the time they spent giving interviews and sharing their reflections with the fieldworker.

\section{Funding}

The study is part of a Ph.D. funded by the University of Southern Denmark, the Department of Research at the Hospital of Southern Jutland (Sygehus Sønderjylland) and The Health Foundation (Sygekassernes Helsefond).

\section{Notes}

1: In Denmark, local community healthcare centres have the principal responsibility for preventive healthcare services. For instance, they offer a range of patient education programmes for people with chronic diseases.

2: Early retirement can be approved if it is documented that a person suffers from a considerably and permanently reduced capacity to work - for example due to chronic illness.

3: A number of conditions apply to a subsidized job. Approval to undertake a subsidized job is based on documented evidence that a person suffers from a permanent reduction in his or her capacity to work. The employer is refunded a proportion of the person's salary.

4. Berger and Luckmann describe the "stock of knowledge" as the commonsense knowledge that we develop from the everyday life world in which we are engaged. We have elaborated this concept a little further. We refer to the "stock of illness-related knowledge" as a description of the first-person knowledge about living with a chronic illness that develops when a person has lived with chronic illness for a period of time. This knowledge is shaped both by how a person handles the illness and experiences of living with a chronic condition, and by encounters with the health system that may or may not enhance the person's understanding of their chronic condition.

\section{References}

Aggergaard Larsen,J. (2010). Identiteten. Dialog om forandring. (Identity. Dialogue about change). In Kirsten Hastrup (Ed.), Ind i verden - en grundbog $i$ antropologisk metode (Into the world - an introduction to anthropological methods) (pp. 247-271). Copenhagen: Hans Reitzels Forlag.

Atkinson,P. (1995). Pearls, Pith and Provocation. Some perils of paradigms (1995). Qualitative Health Research 5(1), 117-124.

Barnes,M., Newman,J., Knops,A. \& Sullivan,H. (2003). Constituting »the public« in public participation. Public Administration 81 (2), 379-399. 
Bech-Jørgensen,B. Når Hver dag Bliver Hverdag (When Every day Becomes the Everyday). (1994). Aalborg Universitet (University of Aalborg).

Bech-Jørgensen,B. (2002). Forskning og hverdagsliv (Research and Everyday Life). Forskningsgruppen Arbejds- og levemiljøer 7(1), 3-48.

Berger,P.L., \& Luckmann,T. (1966). The Social Construction of Reality. A treatise in the Sociology of Knowledge. New Youk, USA: Penguin Books.

Bury,M. (1982). »Chronic Illness as biographical disruption«. Sociology of health and illness $4(2), 167-195$.

Church,J., Saunders,D., Wanke,M., Pong,R., Spooner,C., \& Dorgan,M. (2002). Citizen Participation in Health Desicion-Making: Past Experiences and Future Prospects. Journal of Public Health Policy 23(1), 12-32.

Coffey,A. \& Atkinson,P. (1996). Making Sense of Qualitative Data: Complementary Research Strategies. London, Thousand Oaks, CA and New Delhi: Sage Publications.

Contandriopoulos,D. (2004). A sociological perspective on public participation in health care. Social Science and Medicine 58 321-330.

Coulter A. \& Ellins J. (2006). Patient-focused interventions. A review of the evidence. Picker Institute Europe.

Crawford,M.J., Rutter,D, Manley,C, Weaver,T., Bhui,K, Fulop,N., \& Tyrer,P. (2002). Systematic review of involving patients in the planning and development of health care 325 , BMJ. 1293-1269.

Emerson,R.M., Fretz,R.I., \& Shaw,L.L. (1995). Writing Ethnographic Fieldnotes. Chicago: The University of Chicago Press.

Fox,J. (2011). »The view from inside«: understanding service user involvement in health and social care education. Disability \& Society 26(2), 169-177.

Freil M. \& Lehmann Knudsen J. (2009). Brugerinddragelse i Sundhedsvæsenet (User involvement within the Health Care System). Ugeskrift for Læger (Weekly Journal for General Practitioners) 171(20), 1663-1666.

Fudge,N., Wolfe,C.D., McKevitt,C. (2008). Assessing the promise of user involvement in health service development: ethnographic study. BMJ online first 1-8.

Gannik, D. E. (2005). Social sygdomsteori - et situationelt perspektiv (social theory of illness - a situational perspective, Frederiksberg C: Forlaget Samfundslitteratur.

Hammersley,M \& Atkinson,P. (2007). Ethnographic principles in practice, 3rd. edition, USA and Canada: Routledge.

Hastrup,K. (2009). Videnskabelig praksis. Det etiske felt i antropologien (Research practice. Ethics in anthropology«, in Kirsten Hastrup (ed.), Mellem mennesker. En grundbog $i$ antropologisk forskningsetik (Among human beings. An introduction to anthropological research ethics), (pp. 9-30). Copenhagen: Hans Reitzels Forlag.

Hodge,S. (2005). Participation, discourse and power: a case study in service user involvement. Critical Social Policy 25 164-179.

Hviid Jacobsen,M., \& Kristiansen,S. (2006). Farligt feltarbejde -etik og etnografi $i$ sociologien (Dangerous fieldwork - ethics and ethnography in sociology). Aalborg: Aalborg Universitetsforlag

Jenkins,R. (2008). Social Identity. London and New York: Routledge.

Kleimann,A. (1988). The illness narratives. Suffering, healing and the human condition. New York Basic Books, Inc. 
Kristiansen,T., Primdahl,J., Antoft,R., \& Hørslev-Petersen,K. (2012). Everyday Life with Rheumatoid Arthritis and Implications for Patient Education and Clinical Practice: A Focus Group Study. Musculoskeletal Care 10 162-170.

Martin,G.P. (2008a). »Ordinary people only«. knowledge, representativeness, and the publics of public participation in healthcare. Sociology of health and illness 30(1), 35-54.

Martin,G.P. (2008b). Representativeness, legitimacy and power in public involvement in health-service management. Social Science and Medicine 67 1757-1765.

Martin,G.P., \& Finn,R. (2011). Patients as team members: opportunities, challenges and paradoxes of including patients in multi-professional healthcare teams. Sociology of health and illness 33(7), 1050-1065.

Nettleton,S., \& Burrows,R. (2003). E-Scaped Medicine? Information, Reflexivity and Health. Critical Social Policy 23 165-184.

Reddel T, \& Woolcock,G. (2004). From consultation to participatory governance? A critical review of citizen engagement strategies in Queensland. Australian Journal of Public Administration 63(3), 75-87.

Schutz,A. (2005). Hverdagslivets Sociologi - en Tekstsamling (The Sociology of Everyday Life - a Collection of Texts). København (Copenhagen): Hans Reitzels Forlag.

Templer C.B, \& Nowak, P. (2011). Consumer participation and organizational development in health care: a systematic review. Wiener klinische Wochenschrift.

Wadel,C. (1991). Feltarbeid $i$ egen kultur - en innføring $i$ kvalitativt orientert samfunnsforskning(Fieldwork in your own culture - an introduction to kvalitative social research). Flekkefjord, Norge (Norway): SEEK a/s.

Willis,K.F, Robinson,A, Wood-Baker,R., Turner,P, \& Haydn Walters,E. (2011). Participation in Research: Exploring Participation and Engagement in a Study of Self-Management for People with Chronic Obstructive Pulmonary Disease. Qualitative Health Research 21(9), 1273-1282.

Ziebland,S. (2004). The importance of being expert: the quest for cancer information on the Internet. Social Science and Medicine 59 1783-1793. 